\title{
Embebição e qualidade fisiológica de sementes de tremoço branco tratadas com micronutrientes
}

\author{
Imbibition and white lupine seeds physiological quality affected by micronutrients supply
}

\section{Lilian Guimarães de Almeida ${ }^{I}$ Aldeane Sousa BrandãoII Claudia Antonia Vieira Rossetto ${ }^{\text {II }}$}

\section{RESUMO}

As sementes de tremoço branco, devido ao alto teor de óleo e proteína, estão sendo cada vez mais utilizadas na alimentação humana e animal. Dessa forma, o objetivo deste trabalho foi avaliar a embebição e a qualidade fisiológica de sementes de tremoço branco tratadas via imersão em soluções de micronutrientes. Os tratamentos constaram do controle (isento de imersão), imersão em água destilada e em soluções de $\mathrm{Cu}$, $B, \mathrm{Zn}, \mathrm{Mn}$ e Mo, em delineamento experimental inteiramente casualizado. A avaliação da embebição e qualidade fisiológica foi através de testes de germinação e de vigor (primeira contagem de germinação, condutividade elétrica e crescimento de plântulas), bem como a determinação do teor de nutrientes. A velocidade de absorção das sementes de tremoço branco com menor qualidade fisiológica inicial, na presença de Mn e Mo, diminui, enquanto o tratamento de sementes de tremoço branco via imersão em soluções de micronutrientes favorece a sua qualidade fisiológica.

Palavras-chave: Lupinus albus L., potencial osmótico, condicionamento.

\section{ABSTRACT}

White lupine seeds due to the high oil content and protein are being used in animal and human feed, so the objective was to evaluate the absorption and white lupine seeds physiological quality that were treated by immersion in micronutrients solutions. Treatments consisted of control (free immersion), immersion in distilled water and in solutions of $\mathrm{Cu}, \mathrm{B}, \mathrm{Zn}, \mathrm{Mn}$ and $\mathrm{Mo}$ in a completely randomized design. Evaluation of absorption and physiological quality was through seed germination and vigor (first count, electrical conductivity and seedling growth) as well as determining the nutrient content tests. The absorption rate of white lupine seeds with lower initial quality in the presence of Mn and
Mo decreases. The treatment of white lupine seeds by immersion in solutions of micronutrients favors the physiological quality.

Key words: Lupinus albus L., osmotic potential, priming.

\section{INTRODUÇÃO}

O tremoço branco (Lupinus albus L.) pertence à família Fabaceae. Ele pode ser utilizado, dentre outras formas, para consumo humano e animal devido principalmente ao alto teor de proteínas e de óleo em suas sementes (HUYGHE, 1977).

Para obtenção de elevada produtividade de sementes, é importante dar ênfase à qualidade fisiológica das que serão usadas na semeadura. Esta qualidade depende, dentre outros, da disponibilidade de macro e micronutrientes às plantas progenitoras (CARVALHO \& NAKAGAWA, 2000). No entanto, os micronutrientes, exigidos em menor quantidade (OLIVEIRA et al., 2010), exercem papel diferenciado nas plantas e agem como co-fatores nos sistemas de enzimas, além de estarem envolvidos em reações redox (FAROOQ et al., 2012).

$\mathrm{O}$ fornecimento de micronutrientes vem sendo realizado via aplicação foliar ou via tratamento pré-semeadura, pela imersão das sementes em solução com concentração pré-estabelecida de específico micronutriente, por determinado período,

IPrograma de Pós-graduação em Fitotecnia (PPGF), Instituto de Agronomia, Universidade Federal Rural do Rio de Janeiro (UFRRJ), Seropédica, RJ, Brasil.

"Curso de Agronomia, UFRRJ, Seropédica, RJ, Brasil.

IIIDepartamento de Fitotecnia, UFRRJ, BR 465, km 7, 23851-970, Seropédica, RJ, Brasil. E-mail: cavrosse@ufrrj.br. Autor para correspondência. 
bem como pela adição diretamente às sementes no momento da semeadura, ou ainda, pelo procedimento de peletização.

O tratamento de imersão é denominado condicionamento com nutrientes ou nutricondicionamento (FAROOQ et al., 2009), pois, além do fornecimento de nutrientes às sementes, ocorre o controle da velocidade de embebição e a inicialização do processo metabólico sem a ocorrência da germinação, como proposto por HEYDECKER et al. (1975).

O nutricondicionamento tem proporcionado diminuição no período de embebição (TAYLOR et al., 1998) de lixiviados metabólicos (BASRA et al., 2005) e, também, maior sincronização da germinação (FAROOQ et al., 2009). Em outras espécies, tais como mamona, OLIVEIRA et al. (2010) verificaram que a imersão em soluções de ácido molíbdico e sulfato de ferro favoreceu a germinação e o vigor nas sementes de caupi e grão de bico; JOHNSON et al. (2005) constataram aumento da germinação e vigor após imersão em soluções de molibdato de sódio, ácido bórico e sulfato de zinco.

Dentro deste contexto, o objetivo foi analisar a embebição bem como a germinação e o vigor de sementes de tremoço branco após a submissão ao tratamento via imersão em soluções de micronutrientes.

\section{MATERIAL E MÉTODOS}

O experimento foi conduzido em 2012, adotando o delineamento experimental inteiramente casualizado em esquema fatorial $3 \times 7$ (lotes e tratamentos pré-semeadura), em quatro repetições. Foram utilizados três lotes de sementes de tremoço branco (Lupinus albus L.) da cultivar 'Comum' da safra 2011, previamente tratadas com $2 \mathrm{~g} \mathrm{~kg}^{-1}$ de Orthocide (p.a captam), que permaneceram armazenadas por um mês a $17^{\circ} \mathrm{C}$ e $46 \%$ de umidade relativa do ar, antes do início dos testes.

Os tratamentos foram representados pelo controle (isento de imersão), imersão em água destilada e em solução de boro (B), zinco ( $\mathrm{Zn})$, cobre $(\mathrm{Cu})$, manganês $(\mathrm{Mn})$ e molibdênio (Mo), cujas fontes utilizadas e as respectivas concentrações foram: ácido bórico - $\mathrm{H}_{3} \mathrm{BO}_{3}\left(0,02 \mathrm{~mol} \mathrm{~L}^{-1}\right.$ de B), sulfato de zinco $\mathrm{ZnSO}_{4}\left(0,002 \mathrm{~mol} \mathrm{~L}^{-1} \mathrm{de} \mathrm{Zn}\right)$, sulfato de cobre - $\mathrm{CuSO}_{4}$ $\left(0,0005 \mathrm{~mol} \mathrm{~L}^{-1} \mathrm{de} \mathrm{Cu}\right)$, sulfato de manganês - $\mathrm{MnSO}_{4}$ $\left(0,002 \mathrm{~mol} \mathrm{~L}^{-1}\right.$ de $\left.\mathrm{Mn}\right)$ e ácido molíbdico $-\mathrm{H}_{2} \mathrm{MoO}_{4}$, $\left(0,0005 \mathrm{~mol} \mathrm{~L}^{-1}\right.$ de Mo), com base em OLIVEIRA et al. (2010).

A avaliação da embebição foi realizada com quatro subamostras de 400 sementes (125g), por lote e tratamento, imersas em $600 \mathrm{~mL}$ de água destilada e em soluções de micronutrientes e mantidas a $20^{\circ} \mathrm{C}$ durante duas, quatro, seis, oito e doze horas. Após cada período, as sementes foram submetidas à secagem superficial e à pesagem em balança digital com três casas decimais. Para avaliação da quantidade de água absorvida pelas sementes, foram considerados o grau de umidade e o peso inicial da amostra, com base em ROSSETTO \& MARCOS FILHO (1995), sendo os resultados expressos em porcentagem de água.

$\mathrm{Na}$ avaliação da qualidade fisiológica (germinação e vigor), foram utilizadas quatro amostras de 400 sementes por lote e tratamento, imersas em água destilada e em soluções de micronutriente, por duas horas, em sistema aerado com bomba do tipo aquário (LOPES, ROSSETTO, CARNEIRO, 2000) a $20^{\circ} \mathrm{C}$. Posteriormente, estas foram secas a $30^{\circ} \mathrm{C}$ por 12 horas (BARROS \& ROSSETTO, 2009), sendo que as sementes do tratamento controle não foram submetidas à imersão.

O teste de grau de umidade foi realizado com quatro subamostras de 50 sementes moídas e mantidas a $130 \pm 3^{\circ} \mathrm{C}$ por uma hora (BRASIL, 2009). Para a instalação do teste de germinação, quatro subamostras de 50 sementes, por lote e tratamento, previamente submetidas à superação de dormência por sete dias a $5^{\circ} \mathrm{C}$ (BRASIL, 2009), foram distribuídas em papel toalha (germitest) e mantidas a $20^{\circ} \mathrm{C}$ na ausência de luz. As avaliações foram realizadas aos 5 e 10 dias após a instalação (BRASIL, 2009), sendo os resultados expressos em porcentagem de plântulas (normais e anormais).

O vigor foi avaliado através dos testes de: primeira contagem - realizado em conjunto com o teste de germinação, considerando a porcentagem de plântulas normais aos cinco dias após a instalação (NAKAGAWA, 1999); crescimento de plântulas - conduzido com quatro repetições de 10 sementes, por lote e tratamento, distribuídas em papel toalha (germitest) e mantidas a $20^{\circ} \mathrm{C}$ na ausência de luz. A avaliação foi realizada aos cinco dias da instalação, sendo que as plântulas normais, previamente avaliadas quanto ao comprimento, tiveram seus cotilédones separados do hipocótilo e foram submetidas à secagem em estufa, regulada a $65^{\circ} \mathrm{C}$ para avaliação da matéria seca (NAKAGAWA, 1999), sendo os resultados expressos, respectivamente, em cm e g/plântula; condutividade elétrica - realizado com quatro repetições de 50 sementes, por lote e tratamento, 
previamente pesadas e imersas em $75 \mathrm{~mL}$ de água destilada, durante 24 horas a $20^{\circ} \mathrm{C}$ (SANTOS et. al., 2004), sendo a avaliação realizada em condutivímetro e os resultados expressos em $\mu \mathrm{S}$ $\mathrm{cm}^{-1} \mathrm{~g}^{-1}$

Para análise da concentração de micronutrientes, o delineamento experimental adotado foi o inteiramente casualizado em esquema fatorial 3x2 (lotes e tratamentos) em quatro repetições, para cada micronutriente avaliado. Para isso, foram utilizadas sementes dos três lotes de tremoço branco e os tratamentos representados por sementes não imersas (controle) e imersas por duas horas em distintas soluções, conforme o micronutriente. Assim, por lote e tratamento, quatro repetições de 50 sementes (15 gramas), previamente moídas, foram submetidas à digestão nitro-perclórica (MALAVOLTA et al., 1997) para determinação de $\mathrm{Cu}, \mathrm{Mn}, \mathrm{Zn}$ e B; outras quatro repetições de 50 sementes foram encaminhadas para determinação de Mo, por meio de espectometria de emissão de plasma (SILVA, 2009).

Os dados obtidos foram submetidos à análise de variância e as médias comparadas pelo teste Tukey a $5 \%$ de probabilidade. Também foi realizada a análise de regressão, sendo a escolha da equação realizada com base na expectativa biológica e no coeficiente de regressão (PIMENTEL-GOMES, 2009).

\section{RESULTADO E DISCUSSÃO}

$\mathrm{Na}$ avaliação da embebição das sementes de tremoço branco, houve efeito significativo da interação entre lotes e períodos de imersão em soluções de micronutrientes, exceto as de $\mathrm{B}$ e $\mathrm{Cu}$. As sementes do lote 2 atingiram grau de umidade próximo a 60\% após seis horas de imersão em água destilada e, quando imersas em solução de $\mathrm{Zn}$, somente após oito horas, enquanto, em solução de Mn e de Mo, foi após doze horas (Figura 1), sendo estes valores superiores aos dos lotes 1 e 3 .

Dessa forma, na presença de micronutrientes, ocorreu diminuição da velocidade de absorção de água, como também constatado por FAROOQ et al. (2009), cujo resultado está provavelmente relacionado ao menor potencial fisiológico das sementes do lote 2 (Tabela 1), pois sementes em estado mais avançado de deterioração iniciam a embebição de forma mais rápida (MARCOS FILHO, 2005) e também podem estar associados ao potencial osmótico da solução, que foi de $-0,048 \mathrm{MPa}$ para B e entre $-0,0003$ a $-0,048 \mathrm{MPa}$ para as demais
As tensões de $-0,01$ a $-0,04 \mathrm{MPa}$ são consideradas favoráveis à embebição e consequentemente à germinação das sementes, bem como a velocidade de absorção de água é inversamente proporcional ao aumento da tensão (MARCOS FILHO, 2005). Comparando os resultados, em feijão, SMIDERLE et al. (2008) verificaram que as sementes imersas em água e em soluções de Mo e Zn não diferiram quanto à marcha de embebição, para as sementes de três cultivares estudadas.

Em relação à qualidade fisiológica, foi constatado efeito isolado dos lotes para germinação e vigor (primeira contagem e condutividade elétrica). Assim, independente do tratamento, a qualidade fisiológica (avaliada pelos testes de germinação e condutividade elétrica) das sementes do lote 2 é inferior à dos demais lotes, embora os valores não tenham diferido das sementes do lote 3 (Tabela 1). Este resultado provavelmente pode estar associado à permeabilidade das sementes, como constatado na figura 1 , em que, no lote 2 , verificou-se maior velocidade de embebição.

Ainda pelos dados da tabela 1 , constatouse efeito significativo dos tratamentos pré-semeadura para porcentagem de germinação e de plântulas anormais deformadas, sendo as maiores porcentagens de germinação obtidas com as sementes tratadas via imersão em soluções de Mn e Mo, independente do lote, provavelmente devido à menor porcentagem de plântulas anormais, quando comparadas com as sementes não imersas (controle).

No entanto, estes valores não diferiram estatisticamente dos obtidos com as sementes apenas imersas em água destilada e em outras soluções contendo micronutrientes, o que pode estar associado ao efeito promovido pelo condicionamento das sementes, ou seja, pela hidratação até um determinado nível que tenha promovido o início de eventos metabólicos, como demonstrado por HEYDECKER et al. (1975). Comparando-se os resultados com o de outras espécies, JOHNSON et al. (2005) constataram aumento na germinação, quando as sementes de grão-de-bico e caupi foram imersas em soluções de Mo, B e Zn.

No que se refere ao vigor das sementes, foi observado efeito isolado significativo de tratamentos para porcentagem de plântulas normais na primeira contagem e para condutividade elétrica. Assim, as sementes, independente do lote, que foram tratadas via imersão em água destilada e em todas as soluções contendo micronutrientes, expressaram maior porcentagem de plântulas 

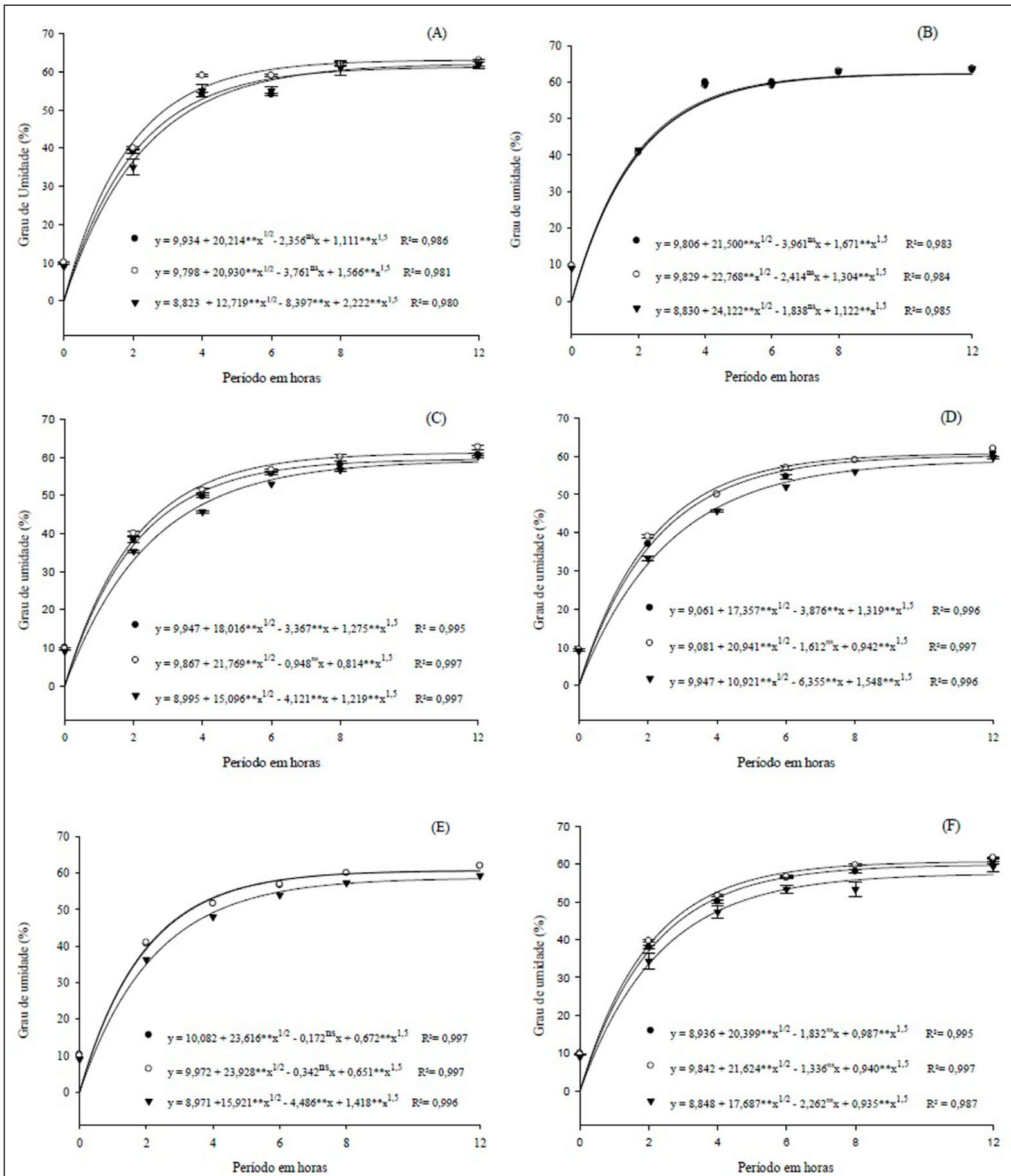

Figura 1 - Curva de embebição das sementes de tremoço branco dos lotes $1(\bullet), 2(\circ)$ e $3(\boldsymbol{\nabla})$, imersas em água destilada (A) e em solução de B (B), $\mathrm{Zn}(\mathrm{C}), \mathrm{Cu}(\mathrm{D}), \mathrm{Mn}(\mathrm{E})$ e Mo (F).

normais e menor valor de condutividade elétrica que as não imersas (controle) (Tabela 1).

Com o condicionamento das sementes, via imersão em soluções com micronutrientes, houve maior sincronização da germinação e também diminuição dos lixiviados metabólicos (Tabela 1), como comentado por FAROOQ et al. (2009) e BASRA et al. (2005), respectivamente. 
Tabela 1 - Germinação (\%), plântulas anormais deformadas (\%), primeira contagem da germinação (\%) e de condutividade elétrica ( $\mu \mathrm{S}$ cm ${ }^{-1}$ $\mathrm{g}^{-1}$ ) de lotes de sementes de tremoço branco após imersão ou não em água destilada e em soluções de $\mathrm{Cu}, \mathrm{B}, \mathrm{Zn}, \mathrm{Mn}$ e Mo.

\begin{tabular}{|c|c|c|c|c|c|c|c|c|}
\hline \multirow{3}{*}{ Tratamentos } & \multicolumn{4}{|c|}{--------------------Lotes-------------------- } & \multicolumn{4}{|c|}{-------------------------Lotes------------------------ } \\
\hline & & & & \multirow[t]{2}{*}{ Médias } & & & & \multirow{2}{*}{ Médias } \\
\hline & 1 & 2 & 3 & & 1 & 2 & 3 & \\
\hline & \multicolumn{4}{|c|}{----------------------Germinação (\%)-------------------- } & \multicolumn{4}{|c|}{--------------Plântulas anormais deformadas (\%)------------- } \\
\hline Sem imersão & $90^{1}$ & 87 & 88 & $88 \mathrm{~b}$ & 9 & 14 & 12 & $12 \mathrm{a}$ \\
\hline Água & 95 & 89 & 94 & $93 \mathrm{ab}$ & 5 & 10 & 6 & $7 \mathrm{ab}$ \\
\hline $\mathrm{H}_{3} \mathrm{Bo}_{3}$ & 95 & 90 & 95 & $93 \mathrm{ab}$ & 6 & 9 & 6 & $7 b$ \\
\hline $\mathrm{ZnSO}_{4}$ & 93 & 93 & 93 & $93 \mathrm{ab}$ & 7 & 7 & 7 & $7 \mathrm{ab}$ \\
\hline $\mathrm{MnSO}_{4}$ & 95 & 97 & 95 & $95 \mathrm{a}$ & 5 & 4 & 5 & $5 b$ \\
\hline $\mathrm{CuSO}_{4}$ & 95 & 92 & 91 & $93 \mathrm{ab}$ & 5 & 9 & 9 & $7 \mathrm{ab}$ \\
\hline $\mathrm{H}_{2} \mathrm{MoO}_{4}$ & 95 & 91 & 95 & $94 \mathrm{a}$ & 5 & 9 & 5 & $6 b$ \\
\hline Médias & $94 \mathrm{~A}$ & $91 \mathrm{~B}$ & $93 \mathrm{AB}$ & & $6 \mathrm{~B}$ & $9 \mathrm{~A}$ & $7 \mathrm{AB}$ & \\
\hline \multirow[t]{2}{*}{ CV(\%) } & \multicolumn{4}{|c|}{1,98} & \multicolumn{4}{|c|}{24,47} \\
\hline & \multicolumn{4}{|c|}{---------------Primeira contagem (\%)--------------- } & \multicolumn{4}{|c|}{-------Condutividade elétrica $\left(\mu \mathrm{S} \mathrm{cm}^{-1} \mathrm{~g}^{-1}\right)$------. } \\
\hline Sem imersão & 86 & 81 & 82 & $83 b$ & 49,75 & 55,33 & 57,57 & $54,22 \mathrm{a}$ \\
\hline Água & 94 & 84 & 92 & $90 \mathrm{a}$ & 20,47 & 23,68 & 28,65 & $24,27 b$ \\
\hline $\mathrm{H}_{3} \mathrm{Bo}_{3}$ & 91 & 85 & 92 & $89 \mathrm{a}$ & 22,51 & 25,01 & 28,53 & $25,35 b$ \\
\hline $\mathrm{ZnSO}_{4}$ & 90 & 88 & 90 & $89 \mathrm{a}$ & 22,04 & 21,83 & 29,14 & $24,34 b$ \\
\hline $\mathrm{MnSO}_{4}$ & 92 & 94 & 92 & $92 \mathrm{a}$ & 22,21 & 25,50 & 35,13 & $27,62 b$ \\
\hline $\mathrm{CuSO}_{4}$ & 90 & 88 & 90 & $89 a$ & 21,06 & 20,99 & 28,89 & $23,64 b$ \\
\hline $\mathrm{H}_{2} \mathrm{MoO}_{4}$ & 91 & 85 & 94 & $90 \mathrm{a}$ & 20,75 & 25,37 & 29,82 & $25,32 b$ \\
\hline Médias & $90 \mathrm{~A}$ & $86 \mathrm{~B}$ & $90 \mathrm{~A}$ & & $25,54 \mathrm{~B}$ & $28,24 \mathrm{AB}$ & $33,96 \mathrm{~A}$ & \\
\hline CV (\%) & & 2,43 & & & & 7,10 & & \\
\hline
\end{tabular}

${ }^{1}$ Médias seguidas da mesma letra maiúscula na linha e minúsculas na coluna não diferem entre si pelo teste de Tukey a $5 \%$.

$\mathrm{Na}$ avaliação do vigor pelo peso da matéria seca e comprimento de plântulas, não foi verificado efeito significativo da interação entre lotes e tratamentos de pré-semeadura, bem como efeito significativo de lotes e tratamentos (Tabela 2). No entanto, em grão de bico, lentilha e caupi, houve redução do comprimento de plântulas após estas terem sido imersas em soluções com concentração média de Mo, Zn e B (JOHNSON, et al., 2005).

Pelos dados da tabela 3 , foi constatado efeito significativo da interação entre lotes e tratamentos (controle e imersão); assim, após a imersão, houve aumento do conteúdo de $\mathrm{B}, \mathrm{Cu}, \mathrm{Mn}$, $\mathrm{Zn}$ e Mo nas sementes de tremoço. O tratamento de imersão em soluções de Zn, B e Mo aumentou estes nutrientes nas sementes de grão de bico e, em soluções de $\mathrm{B}$ e $\mathrm{Zn}$, nas sementes de lentilha (JONHSON et al., 2005). Além disso, para as sementes do lote 2 , tanto as não imersas (controle) como as imersas na presença de Mn, verificou-se maior conteúdo deste micronutriente, que as dos lotes 1 e 3.

Este resultado pode também favorecer a germinação, como constatado pela tendência de maior porcentagem de germinação do lote 2, quando imersas na presença de Mn (Tabela 1), uma vez que, dentre as funções deste micronutriente no processo de germinação, o Mn atua na formação de lignina presente na membrana da parede celular e, consequentemente, pode influenciar na capacidade e na velocidade de absorção de água, bem como alterar a quantidade de lixiviados liberados para o meio (TEIXEIRA et al., 2005). Dentro desse contexto, o tratamento de sementes de tremoço branco com micronutrientes tem o potencial para melhorar a germinação das sementes e, dependendo do nutriente, os teores iniciais destes elementos podem ser aumentados.

\section{CONCLUSÃO}

A velocidade de absorção das sementes de tremoço branco com menor qualidade fisiológica inicial, na presença de Mn e Mo, diminui, enquanto o tratamento de sementes de tremoço branco via imersão em soluções de micronutrientes favorece a sua qualidade fisiológica.

Ciência Rural, v.45, n.4, abr, 2015. 
Tabela 2 - Comprimento de hipocótilo e raiz $(\mathrm{cm})$ e massa seca $(\mathrm{MS})$ de hipocótilo e raiz $\left(\mathrm{g}\right.$ plântula $\left.{ }^{-1}\right)$ de lotes de sementes de tremoço branco após imersão ou não em água destilada e em soluções de $\mathrm{Cu}, \mathrm{B}, \mathrm{Zn}, \mathrm{Mn}$ e Mo.

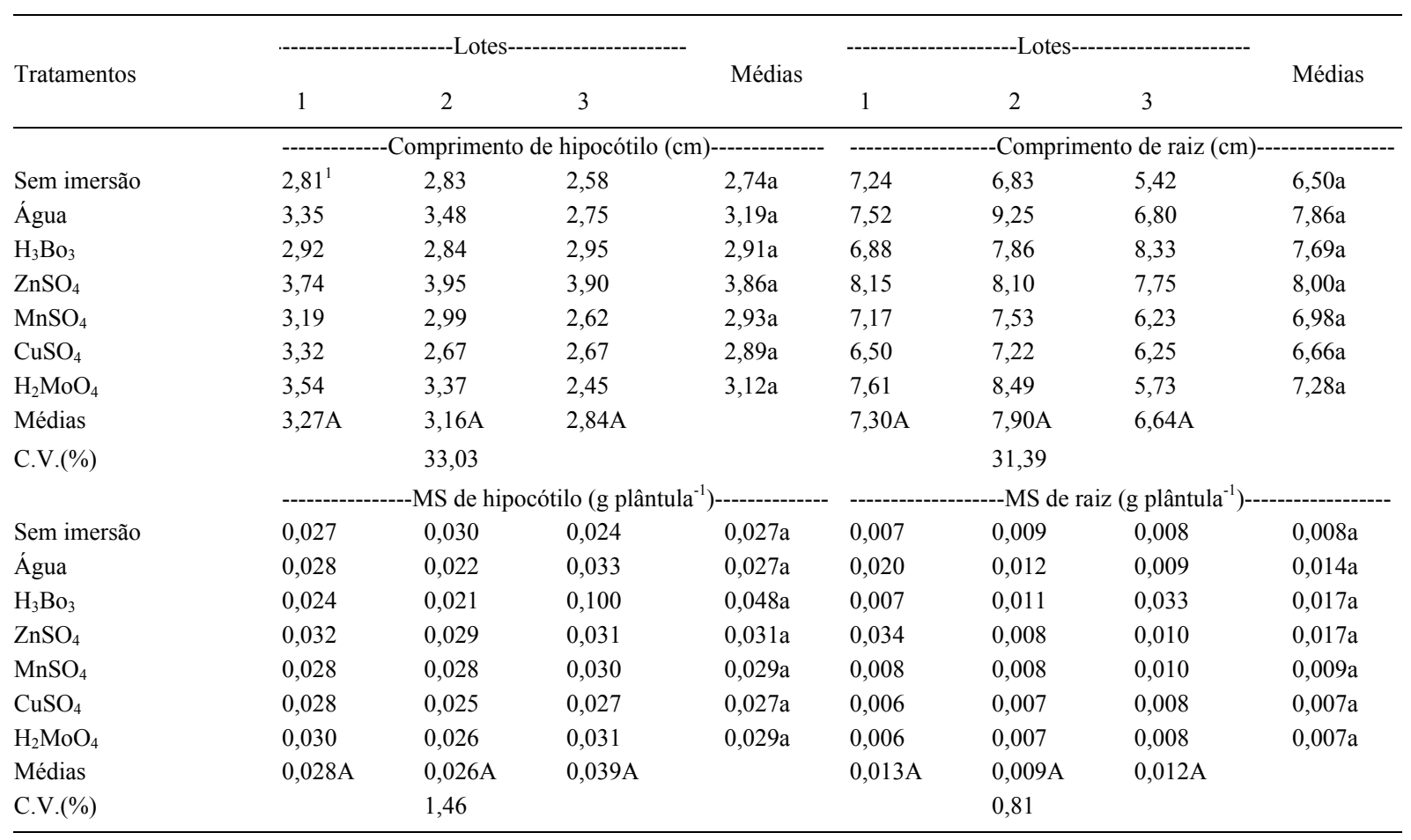

Tabela 3 - Concentração de micronutrientes $(\mathrm{mg} / \mathrm{kg})$ de lotes de sementes de tremoço branco após imersão ou não em água destilada e em soluções de $\mathrm{Cu}, \mathrm{B}, \mathrm{Zn}$, Mn e Mo.

\begin{tabular}{|c|c|c|c|c|c|}
\hline \multirow{2}{*}{ Tratamentos } & & \multicolumn{3}{|c|}{--------------------------------Lotes--------------------------------- } & \multirow{2}{*}{ Médias } \\
\hline & & 1 & 2 & 3 & \\
\hline & & \multicolumn{4}{|c|}{ - } \\
\hline \multirow{2}{*}{$\mathrm{H}_{3} \mathrm{Bo}_{3}$} & Sem imersão & $21 \mathrm{Ab}^{1}$ & $14 \mathrm{Bb}$ & $11 \mathrm{Cb}$ & 15 \\
\hline & Com imersão & $102 \mathrm{Aa}$ & $88 \mathrm{Ba}$ & $87 \mathrm{Ba}$ & 92 \\
\hline \multicolumn{2}{|l|}{ Médias } & 61 & 51 & 49 & \\
\hline \multicolumn{2}{|l|}{$\mathrm{CV}(\%)$} & --------- & $----2,63--$ & ----------. & \\
\hline \multirow{2}{*}{$\mathrm{ZnSO}_{4}$} & Sem imersão & $43 \mathrm{Bb}$ & $40 \mathrm{Bb}$ & $48 \mathrm{Ab}$ & 44 \\
\hline & Com imersão & $190 \mathrm{Ca}$ & $200 \mathrm{Ba}$ & $260 \mathrm{Aa}$ & 217 \\
\hline \multicolumn{2}{|l|}{ Médias } & 116 & 120 & 154 & \\
\hline $\mathrm{CV}(\%)$ & & --------- & $----1,82--$ & -----------. & \\
\hline \multirow{2}{*}{$\mathrm{MnSO}_{4}$} & Sem imersão & $738 \mathrm{Bb}$ & $1153 \mathrm{Ab}$ & $685 \mathrm{Cb}$ & 882 \\
\hline & Com imersão & $1128 \mathrm{Ba}$ & $1224 \mathrm{Aa}$ & $985 \mathrm{Ca}$ & 1098 \\
\hline \multicolumn{2}{|l|}{ Médias } & 933 & 1188 & 813 & \\
\hline \multicolumn{2}{|l|}{$\mathrm{CV}(\%)$} & ---------- & -----0,30--- & - & \\
\hline \multirow{2}{*}{$\mathrm{CuSO}_{4}$} & Sem imersão & $6 \mathrm{Ab}$ & $6 \mathrm{Ab}$ & 7Aa & 6 \\
\hline & Com imersão & $14 \mathrm{Aa}$ & $8 \mathrm{Ba}$ & $7 \mathrm{Ba}$ & 10 \\
\hline \multicolumn{2}{|l|}{ Médias } & 10 & 7 & 7 & \\
\hline \multicolumn{2}{|l|}{ CV(\%) } & --------- & $----16,03$ & ----------- & \\
\hline \multirow{2}{*}{$\mathrm{H}_{2} \mathrm{MoO}_{4}$} & Sem imersão & $0,12 \mathrm{Bb}$ & $0,18 \mathrm{Ab}$ & $0,07 \mathrm{Cb}$ & 0,12 \\
\hline & Com imersão & $2,50 \mathrm{Aa}$ & $2,28 \mathrm{ABa}$ & $1,13 \mathrm{Ca}$ & 1,97 \\
\hline \multicolumn{2}{|l|}{ Médias } & 1,31 & 1,23 & 0,60 & \\
\hline \multicolumn{2}{|l|}{ CV (\%) } & --------- & $----2,17-$ & - & \\
\hline
\end{tabular}

${ }^{1}$ Médias seguidas da mesma letra maiúscula na linha e minúsculas na coluna não diferem entre si pelo teste de Tukey a 5\%.

Ciência Rural, v.45, n.4, abr, 2015. 


\section{AGRADECIMENTOS}

O primeiro e o terceiro autor agradecem a Coordenação de Aperfeiçoamento de Pessoal de Nível Superior (CAPES) e ao Conselho Nacional de Desenvolvimento Científico e Tecnológico (CNPq) pela concessão de bolsa de estudo e de pesquisa, respectivamente.

\section{REFERÊNCIAS}

BASRA, S.M.A. et al. Physiological and biochemical aspects of seed vigor enhancement treatments in fine rice (Oryza sativa L.). Seed Science and Technology, v.33, n.3, p.623-628, 2005. Disponível em: <http://www.ingentaconnect.com/content/ista/ sst/2005/00000033/00000003/art00009\#expand/collapse $>$. Acesso em: 25 abr. 2013

BARROS, C.S.; ROSSETTO, C.A.V. Condicionamento fisiológico de aquênios de girassol. Ciência Rural, v.39, n.6, p.1667-1675, 2009. Disponível em: <http://www.scielo.br/scielo. php?script $=$ sci arttext\&pid $=$ S0103-84782009000600006\&lng $=p t$ $\&$ nrm $=$ iso\&tlng $=$ en $>$. Acesso em: 16 de jul. 2014. doi:10.1590/ S0103-84782009005000136.

BRASIL. Ministério da Agricultura, Pecuária e Abastecimento. Regras para análise de sementes. Secretaria de Defesa Agropecuária. Brasília: MAPA/ACS, 2009. 395p.

CARVALHO, N.M.; NAKAGAWA, J. Sementes: ciência tecnologia e produção. 4.ed. Jaboticabal: FUNEP, 2000. 588p.

FAROOQ, M. et al. Rice seed invigoration. In: LICHTFOUSE, E. (Ed.). Sustainable agriculture reviews. The Netherlands: Springer, 2009. p.137-175

FAROOQ, M. et al. Micronutrient application through seed treatments a review. Journal of Soil Science and Plant Nutrition, v.12, n.1, p.125-142, 2012. Disponível em: <http://www.scielo. cl/scielo.php?pid=S0718-95162012000100011\&script $=$ sci arttext>. Acesso em: 25 jun. 2012. doi: 10.4067/S071895162012000100011

HEYDECKER, W. et al. Invigoration of seed? Seed Science and Technology, v.3, n.3/4, p.881-888, 1975.

HUYGHE, C. White lupin (Lupinus albus L.). Field Crops Research, v.53, n.1, p.147-160, 1997. Disponível em: <http:// www.sciencedirect.com/science/article/pii/S0378429097000282>. Acesso em: 22 fev. 2013. doi: 10.1016/S0378429097000282.

JOHNSON, S.E. et al. A comparison of the effects of micronutrient seed priming and soil fertilization on the mineral nutrition of chickpea (Cicer arietinum), lentil (Lens culinaris), rice (Oryza sativa) and wheat (Triticum aestivum) in Nepal. Experimental Agriculture, v.41, n.4, p.427-448, 2005. Disponível em: <http:// journals.cambridge.org/action/displayAbstract?fromPage $=$ onl ine $\&$ aid $=340923>$. Acesso em: 22 fev. 2013. doi: 10.1017/S00 14479705002851.
LOPES, H.M. et al. Embebição de sementes de cenoura (Daucus carota L.) em diferentes potenciais osmóticos por dois métodos. Revista Brasileira de Sementes, v. 22, n.1, p. 81-87, 2000

MALAVOLTA, E. et al. Avaliação do estado nutricional das plantas: princípios e aplicações. 2.ed. Piracicaba: POTAFOS, 1997. 319p.

MARCOS FILHO, J. Fisiologia de sementes de plantas cultivadas. Piracicaba: FEALQ, 2005. 495p.

NAKAGAWA, J. Testes de vigor baseados no desempenho das plântulas. In: KRZYZANOWSKI, F.C. et al. Vigor de sementes: conceitos e testes. Londrina: ABRATES, 1999. Cap.2, p.1-24.

OLIVEIRA, R.H. et al. Potencial fisiológico de sementes de mamona tratadas com micronutrientes. Acta Scientiarum Agronomy, v.32, n.4, p.701-707, 2010. Disponível em: $<$ http:// www.scielo.br/scielo.php?script $=$ sci arttext\&pid $=\mathrm{S} 1807$ $8621201000400019 \& \operatorname{lng}=\mathrm{pt \& nrm}=\mathrm{iso}>$. Acesso em: 28 jun. 2012. doi: 10.4025/actasciagron.v32i4.4829.

PIMENTEL-GOMES, F. Curso de estatistica experimental. Piracicaba: FEALQ, 2009. 451p.

ROSSETTO, C.A.V.; MARCOS FILHO, J. Comparação entre os métodos de envelhecimento acelerado e de deterioração controlada para avaliação da qualidade fisiológica de sementes de soja. Scientia Agricola, v.52, n.1., p.123-131, 1995. Disponível em $<$ http://www.scielo.br/scielo.php?script=sci arttext\&pid=S010390161995000100020\&lng=pt\&nrm=iso $>$. Acesso em 09 de jul. 2013. doi:10.1590/S0103-90161995000100020.

SANTOS, C.M.R. etal. Alterações fisiológicas e bioquímicas em sementes de feijão envelhecidas artificialmente. Revista Brasileira de Sementes, v.26, n.1, p.110-119, 2004. Disponível em: <http://www.scielo.br/scielo. php?script $=$ sci arttext\&pid=S0101-31222004000100017>. Acesso em: 25 jun. 2012. doi: 10.1590/S0101-31222004000100017.

SILVA, F.C. Manual de análises químicas de solos, plantas e fertilizantes. Brasília: Embrapa Informação Tecnológica, 2009. 627p. Disponível em <http: livraria.sct.embrapa/br/liv_resumos/ pdf00083136.pdf>. Acesso em: 15 jul. 2014.

SMIDERLE, O.J. et al. Tratamento de sementes de feijão com micronutrientes embebição e qualidade fisiológica. Agro@mbiente on-line, v.2, n.1, p.22-27, 2008. Disponível em: <http://revista.ufrr.br/ index.php/agroambiente/article/view/156>. Acesso em: 25 jun. 2012.

TAYLOR, A.G. et al. Seed enhancements. Seed Science Research, v.8, n.2, p.245-256, 1998 . Disponível em: <http://journals. cambridge.org/action/displayAbstract;jsessionid=4D777C60A1 5FDE8513CED81D34891204.journals? fromPage=online\&aid $>$. Acesso em: 22 fev. 2013. doi: 10.1017/S0960258500004141.

TEIXEIRA, I.R. et al. Teores de nutrientes e qualidade fisiológica de sementes de feijão em resposta à adubação foliar com manganês e zinco. Bragantia, v.64,n.1,p.83-88, 2005. Disponível em: $<$ http://www.scielo. br/scielo.php?script=sci arttext\&pid=S0006-87052005000100009>. Acesso em: 25 jun. 2012. doi: 10.1590/S0006-87052005000100009. 